US Army Corps of Engineers $S_{\circledast}$

Engineer Research and

Development Center

Ecosystem Management and Restoration Research Program

Expert Elicitation Workshop for Planning Wetland and Reef Natural and Nature-Based Features (NNBF) Futures

Candice D. Piercy, Safra Altman, Todd M. Swannack,

August 2021

Carra C. Carrillo, Emily R.Russ, and John H. Winkelman 
The US Army Engineer Research and Development Center (ERDC) solves the nation's toughest engineering and environmental challenges. ERDC develops innovative solutions in civil and military engineering, geospatial sciences, water resources, and environmental sciences for the Army, the Department of Defense, civilian agencies, and our nation's public good. Find out more at www.erdc.usace.army.mil.

To search for other technical reports published by ERDC, visit the ERDC online library at https://erdclibrary.on.worldcat.org/discovery. 


\section{Expert Elicitation Workshop for Planning Wetland and Reef Natural and Nature-Based Features (NNBF) Futures}

Candice D. Piercy, Safra Altman, Todd M. Swannack, Carra C. Carrillo, and Emily R. Russ

Environmental Laboratory

US Army Engineer Research and Development Center 3909 Halls Ferry Road

Vicksburg, MS 39180-6199

John H. Winkelman

Coastal Hydraulics Laboratory

US Army Engineer Research and Development Center 3909 Halls Ferry Road

Vicksburg, MS 39180-6199

Final report

Approved for public release; distribution is unlimited.

Prepared for US Army Corps of Engineers

Washington, DC 20314

Under Funding Acct Code U4368940; AMSCO Code 031342 


\section{Abstract}

This special report discusses the outcomes of a September 2019 workshop intended to identify barriers to the consideration and implementation of natural and nature-based features (NNBF) in US Army Corps of Engineers (USACE) civil works projects. A total of 23 participants representing seven USACE districts, the US Army Engineer Research and Development Center (ERDC), and the University of California-Santa Cruz met at USACE's South Atlantic Division Headquarters in Atlanta, Georgia, to discuss how to facilitate the implementation of NNBF into USACE project planning for wetlands and reefs using six categories: (1) site characterization, (2) engineering and design analysis, (3) life-cycle analysis, (4) economic analysis, (5) construction analysis, (6) and operation and maintenance (and monitoring). The workshop identified seven future directions in wetland and reef NNBF research and development:

- Synthesize existing literature and analysis of existing projects to better define failure modes.

- Determine trigger points that lead to loss of feature function.

- Identify performance factors with respect to coastal storm risk management (CSRM) performance as well as ecological performance.

- Focus additional research into cobenefits of NNBF.

- Quantify the economic life-cycle costs of a project.

- Improve technology transfer with regards to NNBF research and topics.

DISCLAIMER: The contents of this report are not to be used for advertising, publication, or promotional purposes. Citation of trade names does not constitute an official endorsement or approval of the use of such commercial products. All product names and trademarks cited are the property of their respective owners. The findings of this report are not to be construed as an official Department of the Army position unless so designated by other authorized documents. 


\section{Contents}

Abstract........................................................................................................................... if

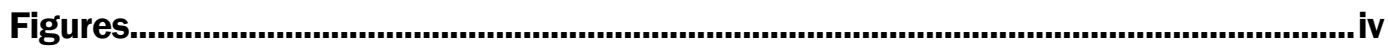

Preface

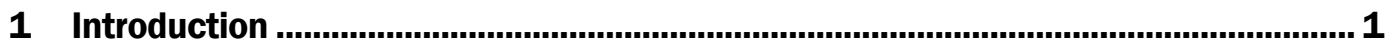

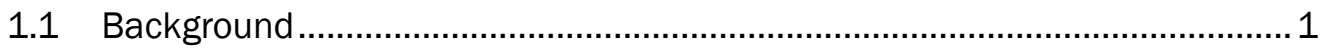

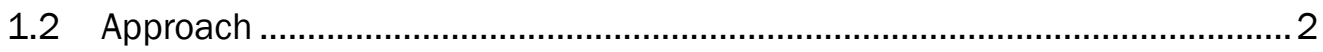

1.3 Objective ............................................................................................

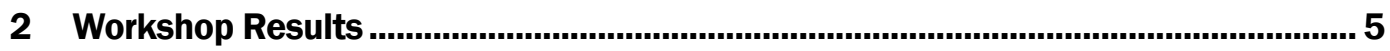

2.1 NNBF implementation challenges summary ............................................ 5

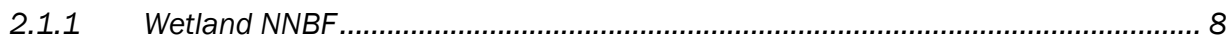

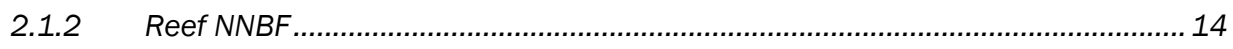

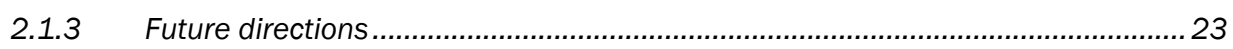

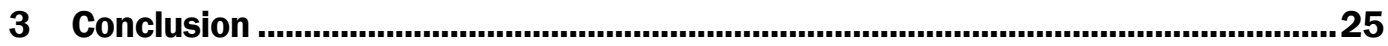

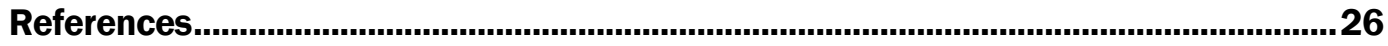

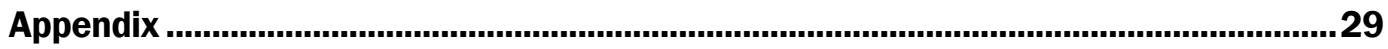

\section{Report Documentation Page}




\section{Figures}

Figures

Figure 1. Identification of participants' primary role in USACE. .......................................... 3

Figure 2. Responses to question, "Rank the aspects of NNBF project

development from hardest to easiest (hardest=6, easiest=1)." ........................................ 5

Figure 3. Participant responses on the types of resources needed to determine NNBF maintenance requirements.................................................................................. 8

Figure 4. Participant comfort level with considering wetlands to achieve CSRM

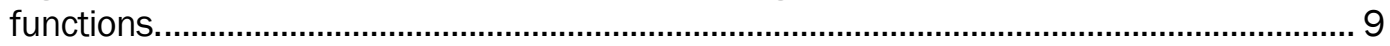

Figure 5. Level of comfort of the workshop participants for using reefs as coastal storm reduction measures.

Figure 6 . Estimate of quantifiability of generalized cobenefits of wetlands and reefs as NNBF. 


\section{Preface}

This report was supported by the US Army Corps of Engineers (USACE) Ecosystem Management and Restoration Research Program (EMRRP) under Funding Account Code U4368940 and AMSCO Code 031342. The USACE Proponent for the EMRRP Program is Ms. Mindy Simmons and on title page instead of the Acting Technical Director is Dr. Jennifer SeiterMoser. The EMRRP Manager was Dr. Brook D. Herman.

The work was performed by the Wetlands and Coastal Ecology Branch of the Ecosystem Evaluation Division, US Army Engineer Research and Development Center, Environmental Laboratory (ERDC-EL). At the time of publication, Patricia Tolley was Branch Chief and Mark Farr was Division Chief. The Deputy Director of ERDC-EL was Dr. Jack Davis and the Director was Dr. Edmond J. Russo.

Technical reviews and suggestions for improvement by Dr. Jeff King and Ms. Mary Bryant are greatly appreciated.

The Commander of ERDC was COL Teresa A. Schlosser and the Director was Dr. David W. Pittman. 


\section{Introduction}

Natural and nature-based features (NNBF) are landscape features used to provide engineering functions relevant to coastal storm and flood risk management while producing additional economic, environmental, or social benefits. Typical NNBF include beaches and dunes, reefs, barrier islands, wetlands, and fluvial floodplains. The NNBF concept was introduced in a brief report on utilizing the full array of coastal risk reduction measures following Hurricane Sandy (USACE 2013), and the concept was further developed in Bridges et al. (2015). Currently, the Water Resources Development Act of $2016^{1}$ requires NNBF measures be considered in all coastal storm risk management (CSRM) studies along with structural and nonstructural measures. The dynamic nature of NNBF requires more complex evaluation techniques to quantify their engineering performance, even in planning stages, compared to structural measures. In September 2019, the US Army Corps of Engineers (USACE) Engineering Research and Development Center's (ERDC) Environmental Laboratory (EL) and Coastal Hydraulics Laboratory (CHL) conducted an expert opinion workshop to determine a path forward for including coastal wetlands-which includes salt marshes, mangroves, coral, and oyster reefs (hereinafter referred to as wetlands and reefs)-NNBF into practical engineering designs for USACE. Wetlands and reefs were chosen because they are the feature types (apart from beaches and dunes) that USACE has the most experience constructing, and they have the largest potential for use in current USACE CSRM feasibility study areas (that is, back bay, harbors, and coastal lagoon areas).

\subsection{Background}

Human development within coastal and fluvial systems is becoming increasingly vulnerable to flooding and storm damage. Factors contributing to these impacts include increased developmental breadth and density in these areas, sea level change, reduced environmental health and degradation resulting in the loss of wetlands, reefs, vegetation. Additionally, the influence of both high-frequency storms (occurring each year or every few 
years) and low-frequency storms (rare catastrophic events), as well as potential compound flooding events, are exacerbating adverse outcomes in these susceptible areas. The structural measures traditionally used for CSRM (for example, seawalls, floodwalls, levees) are expensive to build and maintain. At best, these structures do not enhance environmental function, and at worst, they lead to further degradation at an accelerated rate (Daigneault et al. 2016). Alternatively, NNBF like wetlands and reefs have a natural capacity to mitigate water-level responses to flood and coastal storm events. These features potentially cost less to build and maintain than other structural measures while also restoring or increasing environmental health and function. However, incorporating NNBF into project planning and design can prove challenging for several reasons: (1) the CSRM benefits of NNBF are not as well understood as traditional structural and nonstructural measures; (2) the methods and costs related to the design, construction and long term maintenance of these features is not well documented; (3) the dynamic nature of NNBF requires an understanding of ecosystem processes; (4) NNBF must be managed adaptively to embrace the dynamism; and (5) NNBF have a suite of cobenefits outside of the flood risk reduction benefit that are difficult to quantify using traditional cost-benefits ratios.

In September of 2019, a group of 21 USACE personnel from seven districts and ERDC, and two subject matter experts from University of CaliforniaSanta Cruz, met at South Atlantic Division Headquarters in Atlanta, Georgia, to develop an approach for determining how to better implement two types of NNBF (wetlands and reefs) into USACE project planning and to identify current knowledge gaps and future research needs. See appendix for a complete list of workshop attendees.

\subsection{Approach}

In order to address the multidisciplinary nature of NNBF, the workshop gathered experts from different disciplines throughout USACE, including engineering, environmental works, operations and maintenance (O\&M), planning, and project management (Figure 1). Experts convened for three days, focusing on wetland NNBF for the first half of the workshop (1.5 days) and reef NNBF for the second half. 
Figure 1. Identification of participants' primary role in USACE.

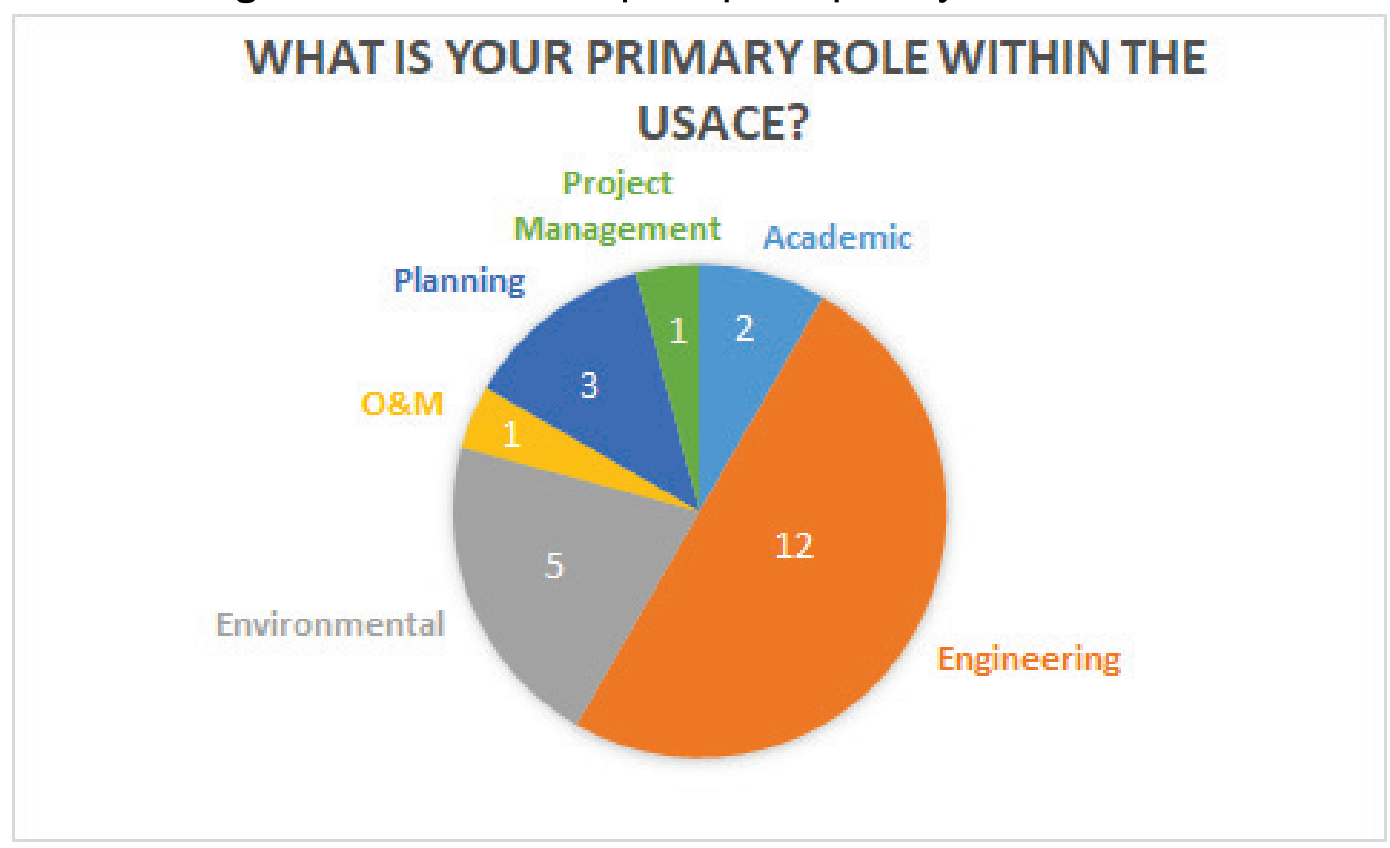

Before the workshop, participants were provided with a detailed questionnaire, which offered participants an opportunity to rank the existing state of knowledge for each of the following six categories:

1. Site characterization

Site characterization pertains to the importance of the past and present physical and ecological conditions and the sediment transport values of a project study area to determine the level of sufficiency to support planning, engineering, construction, operations, and regulatory. It also discusses the ease at which relevant physical and forcing processes of the system and site can be described.

2. Engineering and design analysis

Engineering and design analysis pertains to the ability to design the project performance (calculations) for a NNBF feature with existing knowledge, practice, and tools in an uncertainty-based design framework. It is important to know whether the cost can be performed for the initial design, construction, and maintenance of the feature.

\section{Life-cycle analysis}

When determining what type of NNBF to construct in an area, it is important to determine whether the short- and long-term physical and biological condition of the feature can be evaluated during the life cycle of the 
project in a risk and uncertainty analysis framework. These short- and long-term conditions include evolution of the feature as well as the vegetation evolution and performance.

\section{Economic analysis}

Economic analysis of a feature includes quantifying the economic benefits, social services, and ecosystem goods and services.

\section{Construction analysis}

Construction analysis includes determining whether the NNBF can be constructed and whether the physical and biological impacts to the area, adjacent to the area, and downstream to the area can be quantified and reported in the short and long term.

6. Operations and maintenance (and monitoring)

Operations and maintenance is used to determine whether this feature can be operated and maintained in a predictable manner that allows for the determination of benefits.

\subsection{Objective}

The workshop sought to (1) elicit expert opinion on current engineering perspectives with respect to NNBF, (2) determine what information was needed for NNBF to be viably considered in engineering design, and (3) discuss approaches for the assessment of the costs and benefits of NNBF across the spectrum of cobenefits. 


\section{Workshop Results}

\subsection{NNBF implementation challenges summary}

Participants ranked life-cycle analysis as the most difficult of the six steps in NNBF project development (Figure 2). Many of the concerns involving life-cycle analysis were not unique to NNBF measures. However, since NNBF change and adapt to changes in the physical environment, general unease with life-cycle analysis applied to CSRM studies is amplified when applied to NNBF. Life-cycle analysis requires project delivery teams (PDTs) to understand long-term trends in the environment such as sea level rise (SLR), salinity changes, sediment transport changes, temperature changes, drought frequency. As the physical environment changes, so too will the NNBF and the resulting CSRM benefits that it can provide. Life-cycle methods and tools for NNBF have not yet been developed.

Figure 2. Responses to question, "Rank the aspects of NNBF project development from hardest to easiest (hardest=6, easiest=1)."

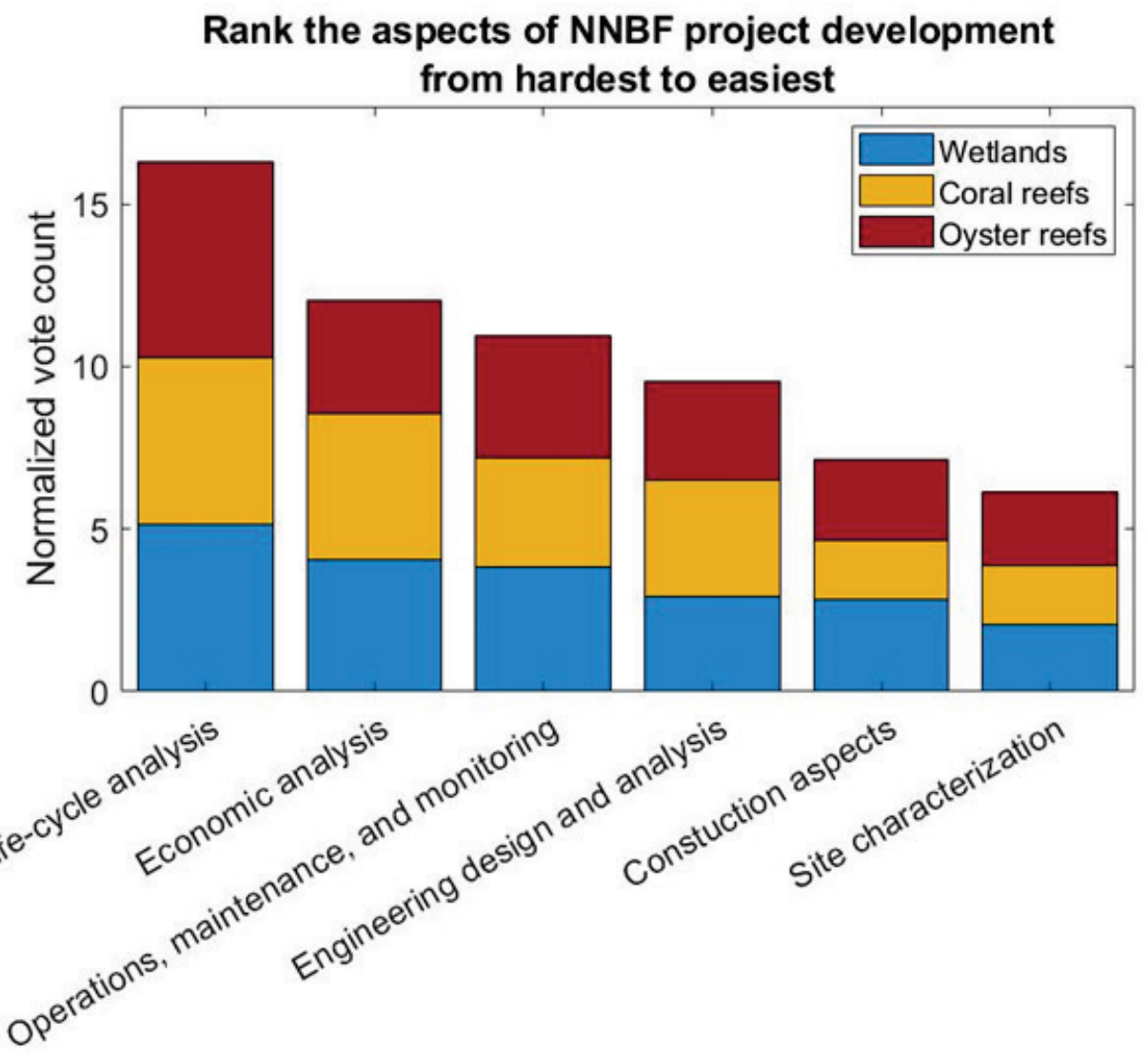


Both economic analysis and operations, maintenance, and monitoring of NNBF are related to life-cycle analysis and were also noted as difficult. From discussions, key uncertainties among workshop participants seemed to be how NNBF would change over time and how that change would affect performance. Critical in determining NNBF performance was determining failure modes and failure thresholds-and under what conditions failure occurred. Some discussion involved the definition of failure, since not all failures lead to the same damages and, therefore, are not equivalent.

Since NNBF rely on ecological function at least in part for their CSRM performance, participants indicated the need to determine which aspects of the ecological system are critical to CSRM function and should be considered and which could be neglected. Participants also stated the need for methodologies to determine NNBF performance with respect to its condition and geometry so that a range of acceptable conditions could be quantified and defined.

Another impediment to NNBF planning and implementation was incorporating potential trade-offs in CSRM performance or habitat types. Habitat conversion, because of extensive restoration or creation of new landscape features, may be a potential stumbling block in the permitting and certification phases of NNBF projects. It is unclear whether habitat-conversion NNBF projects, which may provide a new ecological function, should be burdened with the same mitigation requirements as a structural measure. Participants also identified the need for well-documented demonstration projects as instructional examples for integrating NNBF as part of a complete CSRM study.

Cost engineering was a critical knowledge gap for all NNBF. Participants recommended bringing together cost engineering resources from across USACE, including districts and relevant centers of expertise (for example, Cost Engineering Center of Expertise), to better understand cost estimation not only for NNBF but for all CSRM feasibility studies. Participants cited the limited interaction with cost engineers on PDTs as a potential problem, especially regarding NNBF; they also indicated time and cost estimates could be inaccurate because of incomplete information or faulty assumptions. Uncertainty regarding NNBF performance, whether perceived or real, could also lead to increased costs in an attempt to manage project risk. For example, underpredicting the performance of a reef for 
wave attenuation could lead engineers to overdesign other associated structural measures. Other sources of uncertainty regarding NNBF measures are the potential regulatory hurdles that could lead to project delays.

Workshop participants felt more resources should be allocated to understanding the short-term evolution of NNBF (for example, vegetation damage due to storms or droughts) as opposed to long-term evolution. Shortterm evolution is more likely to be predictable and occur at a timescale relevant to adaptive management. Long-term evolution of NNBF is likely driven by larger-scale system changes that are not exclusive to NNBF and may be best explored separately. Consequently, adaptive management may be required to ensure continued performance, since the long-term environmental changes as well as future disturbances are not well understood for any components of CSRM systems.

Workshop participants felt more documentation of existing NNBF through the development of case studies, examples, and data would allow them to better understand NNBF maintenance requirements, whether they were implemented for CSRM purposes or not (Figure 3). For most of these types of projects, the group acknowledged that operations and maintenance, repair, replacement, and rehabilitation (OMRR\&R) is conducted by the project's local nonfederal sponsor. However, they expressed concern that USACE did not have adequate information, which could be provided to the nonfederal sponsors, to ensure they sufficiently understood the $O M R R \& R$ requirements and the associated timeframe needed to complete these actions for NNBF projects. During the workshop, it was later suggested that a model more akin to beach nourishment may be required for NNBF. In essence, construction should be considered active throughout the life of the project to allow for periodic maintenance. 
Figure 3. Participant responses on the types of resources needed to determine NNBF maintenance requirements.

\section{What resources do you need to better determine} NNBF maintenance requirements?

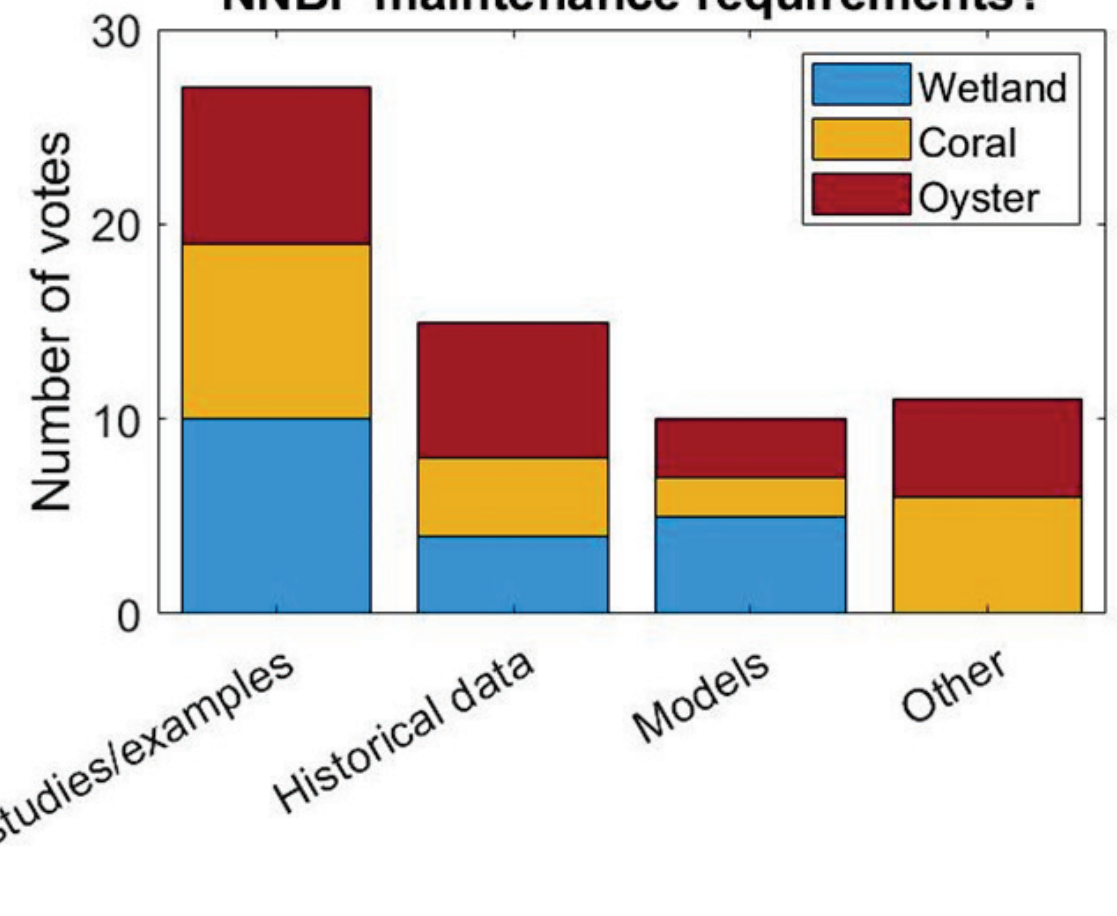

\subsubsection{Wetland NNBF}

Wetland NNBF in the context of this workshop included both marshes and mangroves predominantly in coastal settings. Freshwater wetlands were excluded from the discussion, as they affect coastal storm and flood risk differently enough to warrant separate consideration at a later time. The distinct value of wetlands to attenuate storm and flood risk was also acknowledged during a later meeting of USACE's Coastal Working Group (CWG). According to polling at the Fall 2019 CWG meeting in Washington, DC, most CWG members were interested in tools, methods, and case studies that specifically addressed the use of wetlands in CSRM studies.

Most participants at the September workshop focused on wetland and reef $\mathrm{NNBF}$ felt somewhat comfortable (4 on a scale of 1-5 from not at all comfortable to completely comfortable) with using wetlands to attenuate wind waves not associated with storms and were generally comfortable with using wetlands to reduce erosion and attenuate storm waves (Figure 4). Although participants were less comfortable with using wetlands to attenuate 
surge, encourage accretion, or store flood water, most felt there was sufficient evidence to at least investigate their utility.

Figure 4. Participant comfort level with considering wetlands to achieve CSRM functions.

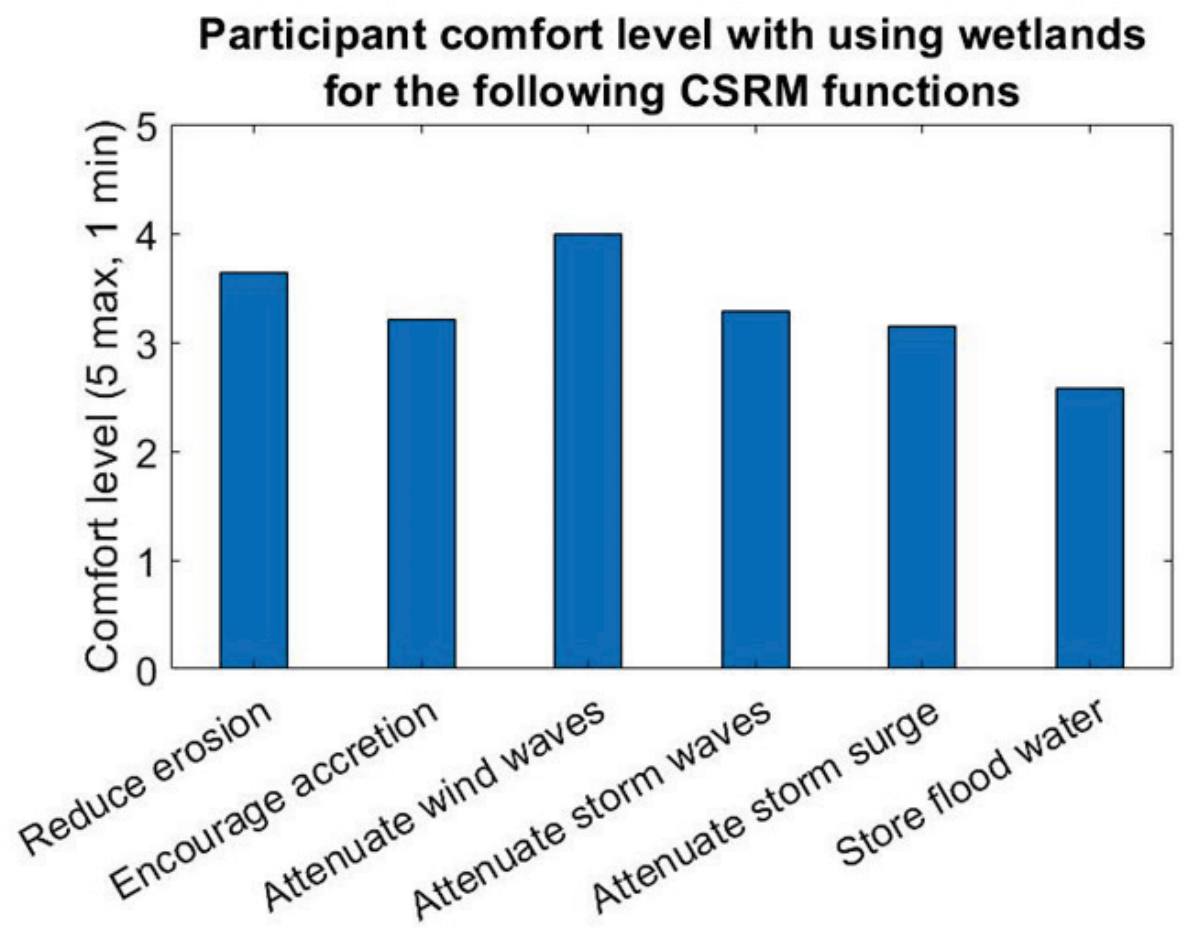

Site Selection and Characterization: Site selection and characterization for wetland NNBF is critical, as location and properties of the wetland strongly control their performance. Most participants felt relatively comfortable with this aspect of project development, although existing data were not always adequate to fully understand site history. For initial site selection, extensive field measurements of local conditions are often not justified. Instead, project teams should use existing wetlands in the immediate area to determine where wetlands can and cannot exist in the environment. Additionally, simple proxy metrics such as unvegetated-tovegetated ratio (Ganju et al. 2017) can screen for likely wetland NNBF locations where actions such as beneficial use of dredged material can improve the condition of existing wetlands, and therefore, possibly increase their CSRM benefit.

Engineering Design and Analysis: Participants identified lack of experience and familiarity with wetlands as an impediment to design as well as conducting life-cycle and economic analyses, especially with regard to maintenance requirements. USACE does not have much guidance on how 
to design and implement wetlands in general and the guidance that does exist (for example, the Wetland Engineering Handbook 2000) is likely outdated. Note that while the current engineer manual on dredged material management (USACE 2015) includes a section on development of wetland habitats, the content is largely the same as it was in the 1987 engineer manual on the beneficial use of dredged material (USACE 1987). However, USACE ecosystem restoration (ER) projects can potentially provide some data necessary to develop design recommendation as well as components essential to life-cycle analysis and maintenance requirements. Although wetland design for ER versus CSRM purposes has some different considerations, existing ER projects also can provide engineers unfamiliar with wetland design some best practices. Other federal and state agencies can also provide some limited guidance for specific types of wetland NNBF, such as the Louisiana Department of Natural Resources Wetland Creation Manual (2018).

Participants discussed what data are required to develop engineering design of wetland NNBF and the level of information required at different stage of the project (for example, feasibility versus design optimization). Participants discussed the need to outline the required design components for wetland NNBF and provide sources of knowledge or information on each component. Some design components discussed included planting design and sediment containment for projects that require construction of new wetland area. Another topic of discussion relative to design was how to manage interactions between the wetland NNBF and the physical environment (for example, waves, bathymetry, sediment transport) to ensure design elements used to protect wetland shorelines did not interfere with other critical physical processes required to sustain wetlands.

Participants disagreed on the ability to model and predict the interaction between wetland NNBF and the physical environment. There was significant disagreement on whether wetland NNBF performance could be adequately predicted given the variability in performance under different storm conditions. While scientific evidence of wetland NNBF performance exists (Gedan et al. 2011; Narayan et al. 2016; Leonardi et al. 2018), it does not cover the range of possible conditions and is biased towards less intense conditions. However, some participants emphasized the role of professional judgment in developing designs and emphasized the inherent uncertainty with designing in any coastal environment. Beach nourishment projects, and their enduring use of simplistic design rules originating 
from similarly incomplete data, were offered as a notable example. Regardless, most participants agreed some statistical analysis of wave- and water-level conditions, coupled with scientific knowledge of wetland performance and failure modes, may be sufficient for initial inclusion of wetland NNBF in a feasibility level design while more robust modeling tools are being developed. More evidence from field studies-as well as demonstration projects and case studies, which are specific to wetland NNBF performance-is preferred over lab studies; however, several participants pointed out that thoughtful lab studies may still be beneficial in some cases.

\subsubsection{Life-Cycle Analysis}

Specific concerns regarding wetland life-cycle analysis included vegetation and marsh face or surface erosion. Wetland CSRM benefits derive from two components: the wetland platform and the vegetation stems. Both are controlled by the vegetation productivity, since the platform elevation is largely controlled by biological accretion. However, loss of plant stems during a storm does not immediately lead to loss of the vegetation itself; vegetation can recover and regrow. During the regrowing period, the marsh face and surface is more susceptible to erosion. To understand how wetland NNBF perform and potentially fail across a life cycle, PDTs must understand the likelihood of both modes of failure across the entire 50year life cycle. If vegetation stems are damaged, the recovery time for the plants must also be estimated. Similarly, wetland NNBF may take time to establish and provide full benefits as the vegetation grows and matures.

Because of the intrinsic ecological value of wetlands, other protected natural resources such as birds may use the wetland environment. However, the habitat value of wetlands used for CSRM purposes should not supersede its primary purpose and inhibit required maintenance activities. Therefore, wetland NNBF require coordination with natural resource agencies. Guidance and case studies resulting from USACE beach fill projects may be helpful in developing a strategy to ensure ecological and CSRM benefits are balanced.

\subsubsection{Economic Analysis}

Workshop participants noted that current economic analysis tools are inadequate for quantifying the reduction in damages related to wetland 
NNBF. Presently, no USACE-approved economics models have the capacity to account for any NNBF or NNBF in combination with structural measures. Even the Generation II Coastal risk model (G2CRM), which includes some protective system elements like floodwalls, cannot integrate $\mathrm{NNBF}$ as a domain consideration. Instead, PDTs must quantify economic damage reduction by simulating the effects of wetlands on water levels through implementation of wetland NNBF within hydrodynamic or wave models, as is the state of practice for the analysis of beaches and dunes. Although inclusion of wetlands in current wave and surge models domains is not trivial, toolkits that will allow simple implementation of NNBF, including wetlands, into existing model domains are currently under development.

Cost-benefit ratios consider a wide range of benefits and costs that can affect local, regional, and national scales and are an important component of project planning, selection, and formulation within USACE and many other federal and nonfederal entities (for example, Federal Office of Management and Budget [OMB], National Oceanic and Atmospheric Administration [NOAA], Environmental Protection Agency [EPA], and the World Bank) (NRC 2004). Workshop participants discussed ways in which wetland NNBF could be used to increase a project cost-benefit ratio, such as adding wetland NNBF in combination with structural measures. This integration has the potential to reduce the size of structural features and thereby reduce the initial construction cost. Vuik et al. (2018) found that the addition of a vegetated foreshore (that is, marsh) reduced the annual failure probability-defined as wave overtopping of or damage to-a dike. In this case, the dike's elevation and toe depth could theoretically be reduced and the need for armoring reduced or eliminated. Maintenance costs may also be reduced, since there will be less interaction between the structure and forcing conditions (that is, less contact with water and waves). Under some conditions, wetland NNBF can cause some waterlevel amplification near the edge of the feature, so insufficiently sized extents of wetland adjacent to structures could potentially lead to amplification of water levels at the structure (Stark et al. 2016); however, sitespecific modeling would determine the extent of the effect and under which conditions it would be likely to occur.

One limitation of cost-benefit ratios is that they rarely capture the noneconomic costs of the feature (for example, environmental services provided 
by NNBF). For example, wetland NNBF benefits such as recreation, biodiversity, and benefits to fisheries are difficult to capture when only considering economic costs. USACE HQ recommends the use of all four accounts from the Principles and Guidelines and Planning Guidance Notebook ( $P \& G$ ) when quantifying cost-benefits of NNBF. More specifically, USACE's National Economic Development (NED) and Environmental Quality (EQ) accounts are mandatory for all feasibility studies, while its Regional Economic Development (RED) and Other Social Effects (OSE) accounts are considered discretionary. In addition, noneconomic factors could be captured under benefits-analysis calculations in the EQ or OSE, while the economic benefits from wetland NNBF should be captured in the NED or RED accounts. However, this multi-tiered approach for cost-benefit calculation was an area that participants identified as requiring additional research and guidance.

\subsubsection{Construction Analysis}

While workshop participants did not find many construction-related barriers to wetland NNBF implementation, they did agree best practices related to wetland construction should be assembled so PDTs unfamiliar with implementing wetland projects could benefit from the experience of others. For wetland NNBF, developing and sharing full technical design specifications throughout USACE and with contracting partners for contractors to follow was identified as an area that could best benefit from shared knowledge across the USACE. The main determinant of a successful wetland NNBF project is the development of regionally appropriate wetland vegetation (for example, native) that provides CSRM functions; however, it can take several years for wetland vegetation to fully develop at a site, so specifications must be written in such a way that the wetland NNBF structure is sufficient for the vegetation to develop. Participants discussed splitting wetland NNBF construction into two stages: the first being earthwork and the second being the actual site planting that only takes place once the sediments are capable of supporting wetland plants. Participants identified another possible tactic that would require contractors to have wetland scientists on-site during construction. Most felt that this requirement would increase the likelihood of success during the construction phase.

Participants also discussed wetland NNBF project certification and communication with resource and regulatory agencies. Development of wetland NNBF may necessitate conversion of open-water areas to intertidal or 
supratidal areas, which can lead to conflict with concerned resource agencies. However, on the basis of experience with the development of existing wetland NNBF projects, there was general consensus among participants that resource agencies were most concerned with potential adverse impacts associated with construction of wetland NNBF. Construction-related activities were thought to produce temporary adverse impacts to the surrounding aquatic environment during and immediately after construction (for example, increased turbidity in waters immediately surrounding the project site) that could lead resource agencies to impose additional constraints, which could then lead to increase project costs.

\subsubsection{Operations, Monitoring, and Maintenance}

Aside from auxiliary structures such as tide gates, wetland NNBF function with minimal intervention; however, routine monitoring is required, and maintenance may be necessary to ensure the wetland NNBF will continue to perform their required CSRM functions. Workshop participants noted the lack of guidance for designing monitoring programs, a lack of monitoring standards, and how to approach wetland NNBF maintenance during the project life (see Figure 3). Vegetation monitoring and maintenance actions were determined to be the most common maintenance activities, especially in regions where invasive wetland species were common. The effects of SLR were of particular concern, since wetland accretion processes are critical to wetland NNBF providing CSRM function for the full life of the project. Considerations for more intensive maintenance actions, such as marsh edge restoration or thin layer placement, were also discussed. Workshop participants generally agreed that management plans should include some performance-based metrics, such as wetland elevation or width, which would trigger more invasive and expensive management actions if appreciable losses were observed during the project's defined life cycle.

\subsubsection{Reef NNBF}

For the purpose of this workshop, we focused on coral and oyster reef NNBF separately as two of the most prominent reef NNBF types with which USACE practitioners would have experience. In considering the CSRM and flood risk management (FRM) benefits provided by reef NNBF, participants indicated that they were most comfortable considering the ability of coral and oyster reef NNBF to attenuate wind waves and storm waves (Figure 5). Additionally, participants were comfortable with using 
oyster and coral reefs for shoreline stabilization. Shoreline stabilization was noted as an important aspect of coral reef features, but participants were not asked to rank this component (that is, there is no coral reef score for shoreline stabilization, Figure 5). Participants were moderately comfortable with the ability of reef features to trap sediment; however, they noted that sediment trapping could affect the reef itself by contributing to increased turbidity and burial, which could negatively affect the reef growing organisms and have cascading effects on the CSRM benefits. Coral reefs differ from oyster reefs in that they can also serve as a source of sediment through sand generation (Perry et al. 2015; Perry et al. 2017). Participants were less comfortable with the prospect of using reefs to attenuate storm surge (Figure 5).

Although there are research gaps that will provide useful information to guide engineering design and analysis, construction, and cost evaluation, workshop participants warned that the hardest step to overcome may be in the planning process itself and justifying the NNBF. The group agreed that the need to translate research and knowledge to policy makers is critical. There is a specific need to communicate the delay in accruing benefits from a reef NNBF project. For example, the maturation of fisheries enhancement benefits derived from reefs such as larger, more valuable, and more biodiverse fish using the reef habitat is typically not observed until the living layer has also developed a biologically and spatially diverse community (Rodwell and Roberts 2000). To manage expectations and plan accordingly, these scientifically reported outcomes should be shared with policy makers and ultimately brought forward into the decision-making process. Workshop participants suggested developing a guidance document that demonstrated a simplified timeline of expected NNBF benefits as one way of accomplishing this desired goal. 
Figure 5. Level of comfort of the workshop participants for using reefs as coastal storm reduction measures.

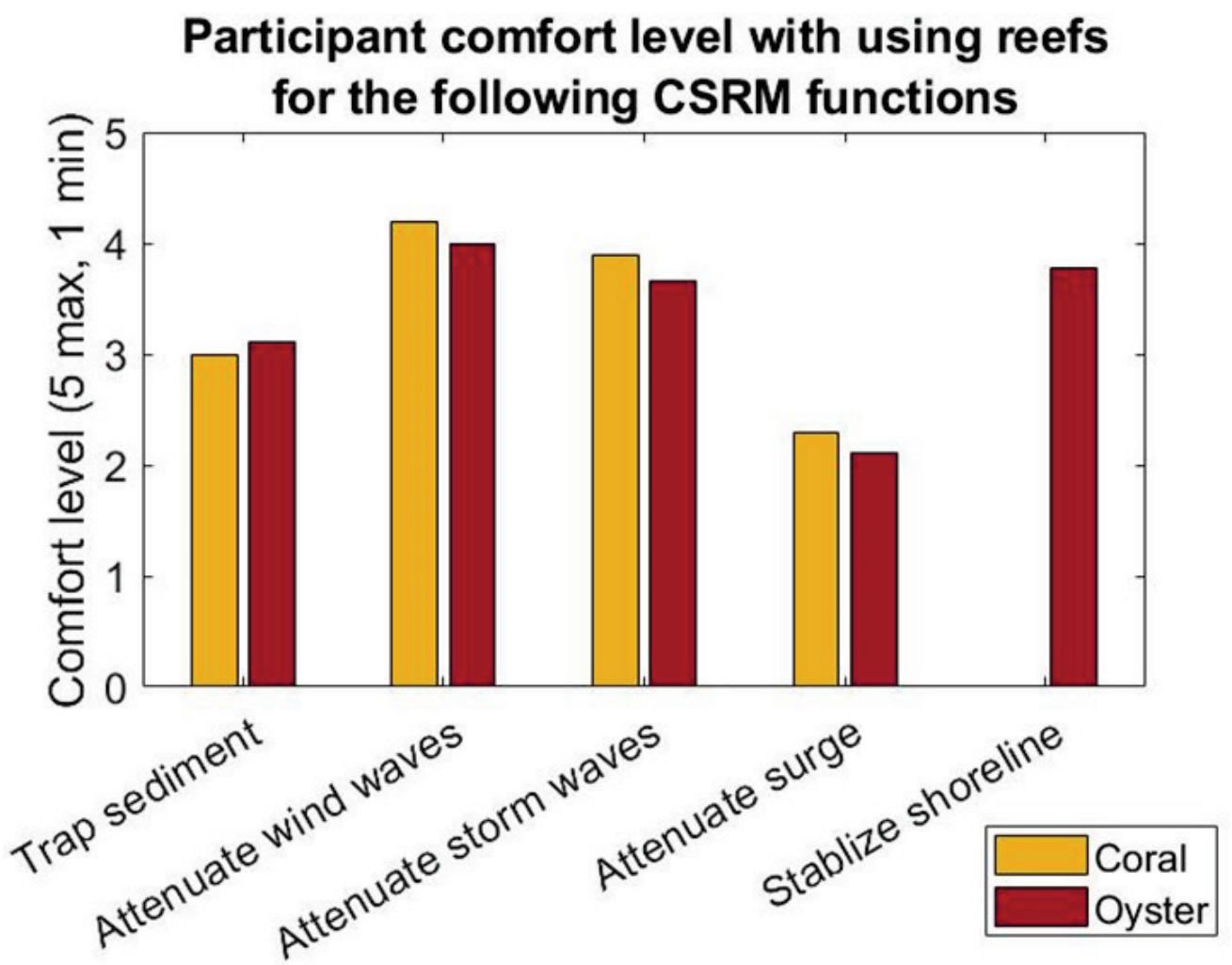

Site Selection and Characterization: When selecting a candidate site for placement of reef NNBF, a critical factor in that evaluation process is the identification and characterization of locations where both CSRM benefits can be achieved and sufficient larval inputs exist. A source of larvae is essential to the health and productivity of a reef. Some sites may have a need for CSRM benefits, such as wind wave attenuation, and have compatible depth and water quality to support coral reef NNBF. However, without a sufficient larval source from nearby reefs, these sites would not be viable for reef NNBF projects. Reef NNBF rely on proximity to other nearby reefs and cannot exist in isolation. This limitation is especially true because aquaculture techniques for transplanting oyster and coral reefs are very site specific and do not have high success, so reef features need nearby reefs to ensure adequate larval input. Another important, site-specific factor in site selection is sediment transport information, such as turbidity, suspended solids, and siltation. These data were perceived as a gap, and participants agreed that data collection was needed to inform site selection. Although the impact of these variables is different depending on the reef type (for example, blocked light due to turbidity affects corals but not oysters), the same data are needed to select sites regardless of reef type. In addition, 
knowledge of fluvial and estuarine inputs that would affect the reef feature is important. Finally, participants indicated a need to distinguish between site characterizations for the goal of restoration as opposed to CSRM outcomes derived from NNBF. Participants also agreed that it was important to ascertain early in the characterization phase if a potential NNBF site is suitable for achieving the desired CSRM benefits and is also able to support a reef.

Engineering and Design Analysis: Workshop participants thought that restoration practices were ripe for adaptation to reef NNBF projects, but they also felt that demonstration projects were needed to focus on understanding the CSRM function in the field at various scales. While participants agreed that coupled ecological and hydrodynamic models were important to engineering design, they thought that existing models could be adapted to new reef NNBF projects. A research effort in support of new, coupled models for planning purposes was not recommended.

In terms of understanding reef performance, participants discussed the need to understand how to define performance depending on the reef type. Because coral grows slowly, an appropriate time frame is needed to determine success of a coral reef NNBF. Primary success may be that the living coral layer is surviving; long-term success may be added coral growth. In addition, performance measures need to integrate CSRM benefits in some way so that the NNBF objectives are measured. One design component that was discussed specifically for coral reef features was the idea of designing and incorporating a gardening program or a restoration plan into the initial upkeep of the feature, which would allow the living layer to adapt to stressors (such as SLR or invasive species).

In discussions about oyster reef performance, participants identified that, while there are a number of substrates available for building oyster reefs (granite, porcelain, moveable breakwaters), more guidance is needed on which materials are best for specific conditions and how to use them in order to optimize oyster attachment and growth. They also discussed the need to understand currents, water flow, and reef positioning for project success. Participants agreed that existing modeling approaches such as particle tracking would help identify locations that might be successful (and locations that would not be ideal). 
In terms of structural design of coral reef features, participants discussed the need for maintaining structural integrity of the substrate. They identified this topic as a research need that would focus on laboratory and field studies to understand how the ecology of the reef and the structural design work together to create a structurally sound feature. They also discussed the importance of the geometry of the built reef platform on wave breaking and acknowledged that the living reef layer would also be important for maintaining that geometry. Finally, they explored the potential to incorporate self-mitigating features in the reef NNBF project. Examples of selfmitigating features that were identified included a project by New York District (USACE-NAN) at Rockaway Beach, where a berm was constructed to accumulate sediment to reduce wetland erosion and increase critical habitat.

\subsubsection{Life-Cycle Analysis}

To understand and evaluate life-cycle analysis of reef features, participants agreed that knowledge of population drivers such as growth rate and recruitment were essential. In addition, a better understanding of the sediment-trapping function of reef NNBF is needed. However, participants did not agree on whether sediment trapping would positively or negatively affect a coral reef feature. That is, trapping sediment within the reef might have a negative impact on the coral while having a positive CSRM impact by reducing erosion. There was more confidence in the ability to predict impacts of sediment trapping than those of transport. Reef dimension is also an important component of life-cycle analysis. Since reef dimensions are expected to change with time, it might be difficult to predict sediment transport and wave attenuation patterns over time; however, some participants noted that there are current informal rules for constructing reefs. While the reef footprint, which is often a built component of a reef feature, is known, predicting reef elevation is more complex, because it is tied to the biological short- and long-term evolution of the reef. With both reef types, there was more confidence in short-term predictions of biological evolution than long-term ones and an understanding that research and maintenance of the living layer of the reef was a requirement. Generally, there was more confidence in understanding the reef footprint-life cycle because the participants had more experience with oyster reef projects.

Participants agreed that investments into predicting reef NNBF life cycles should center on recovery of the living biological layer following disturbance. This focus would reduce uncertainty in reef recovery with respect to 
short-term evolution, which would also contribute to long-term impacts. Although the cues that lead to recruitment of oysters are different from corals, the importance of postdisturbance recruitment and the importance of the biological layer to the NNBF are similar in both reef types. There was consensus that additional information and resources on disease resistance, impacts of acidification, handling organisms at various life stages, and improved modeling were all needed for life-cycle analysis. In general, there was agreement that ample information exists to support life-cycle analysis of reef NNBF, but it is not well documented. Future work should target surveying all USACE districts to compile information on the life cycle of NNBF projects.

In terms of assessing performance of reef NNBF, the greatest research need and most valuable scientific evidence was thought to come from field studies, example case studies, and demonstration projects. Laboratory studies and modeling studies were not deemed to have as much need with respect to performance assessment. For example, estimates of wave reduction and sediment trap efficiency can be calculated with reef dimensions.

\subsubsection{Economic Analysis}

Workshop participants agreed that, while cost information exists for construction, design, and maintenance of both coral and oyster reef NNBF, there is a tremendous need for technical transfer of this information to project planners and engineers. Some important economic details that are not well classified include the value added because of the three-dimensional reef structure or structural complexity and the economic benefit of reef production (recreational and commercial fisheries including bivalves and finfish). Increased three-dimensional structure, or rugosity, equates to a more complex habitat with refuges for various species. This increased habitat complexity results in a more diverse assemblage of associated reef organisms, including economically important species that could contribute to local fisheries and increase tourism (Sebens 1991). Because oyster productivity may lead to fishery pressure on an NNBF feature (which could, in turn, impact its CSRM capability), cost analysis of oyster reef NNBF could have increased complexity, and therefore, benefit from cumulative-effects analysis.

In terms of quantifying economic, environmental, and social benefit and resulting effects, participants felt that the needed principles and guidelines were not developed (Figure 6). Without guidance or formulas to include 
social benefits, they noted that it remains difficult to justify nonmonetary benefits. The group thought that to really move the economic analysis component forward so that it quantitatively includes environmental and social benefits (including recreation as well as benefits that are not yet defined), a cultural change is needed in which the OMB can understand these aspects.

Figure 6. Estimate of quantifiability of generalized cobenefits of wetlands and reefs as NNBF.

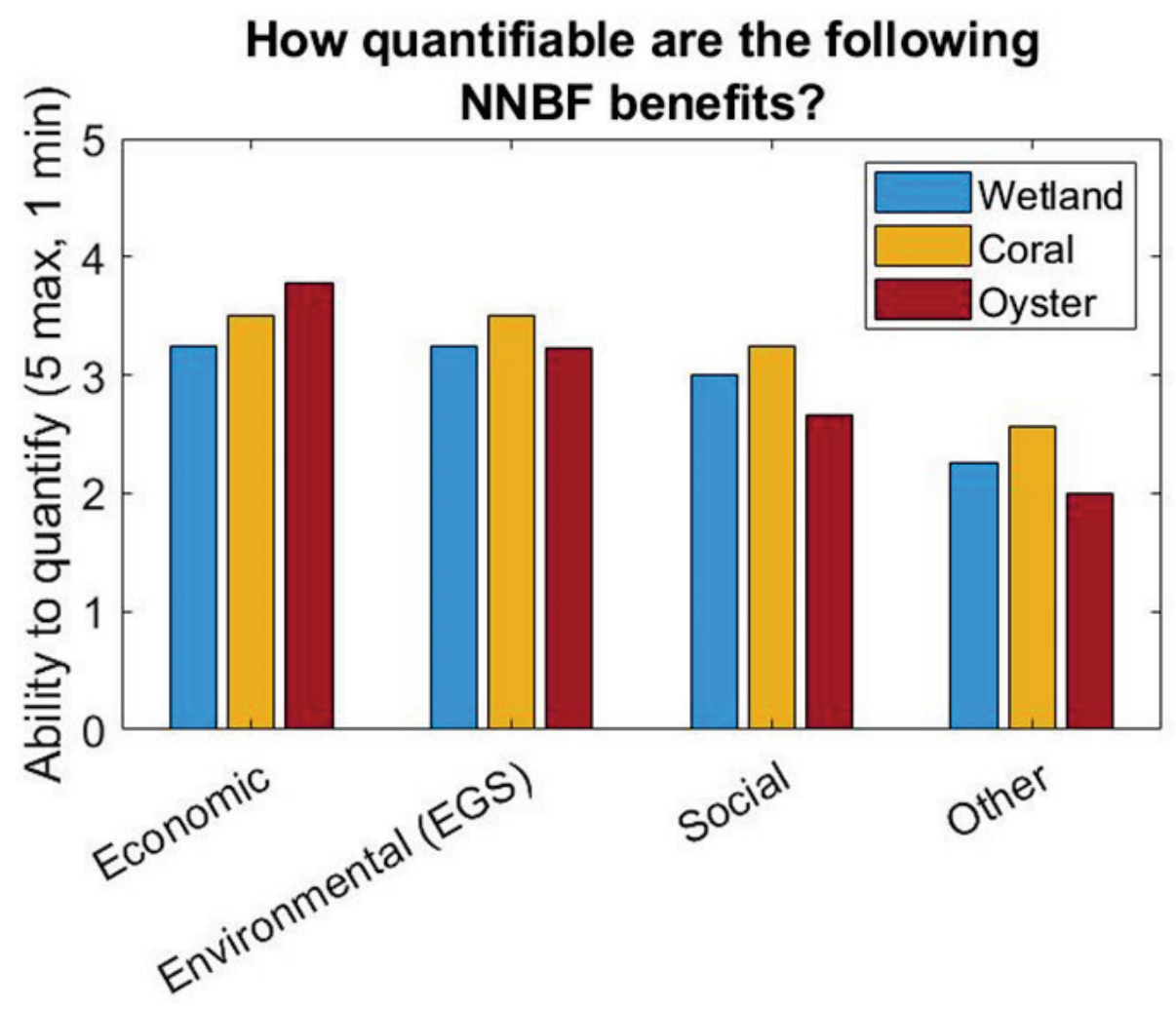

\subsubsection{Construction Analysis}

There are a number of factors to consider when determining the success of reef NNBF from a construction perspective. There is construction success, which denotes the constructed portion of the project meeting the project's design specifications, and there is feature success, which denotes the effectiveness of the design performing as an NNBF. It is challenging to meet the design specifications during the construction phase of a project, and those efforts likely require a survey crew, data analysis, and potentially additional construction. It should be stressed that construction success is critical, because the constructed feature ultimately provides substrate for the living organisms, and it is estimated that $70-90 \%$ of reef NNBF function 
comes from the constructed portion of the feature as a result of depth-induced wave attenuation (Ferario et al. 2014; Narayan et al. 2016; Borja Reguero, pers. comm., Sept. 2019). Because reef NNBF require construction of a submerged platform, which will then be inhabited by live organisms (coral or oyster), the benefits from construction can be assessed in an earlier time frame than the living stage, which requires more time, and the adaptive management stage. For example, if a storm damages the constructed portion of a reef NNBF after it was built but prior to establishment of a living layer, then the nonliving portion of the reef can still be assessed for its CSRM properties. On the other hand, if the living layer was established and was subsequently damaged by a storm, then this outcome would indicate possible failure of the feature. This outcome would also suggest a possible need for adaptive management protocols to address the health and growth of the living layer. Conversely, feature recovery may occur on its own, and understanding the damage level that would trigger adaptive management action is a challenge. Knowing which outcome to anticipate represents an inherent challenge to working with reef NNBF. However, an understanding of the system, coupled with a well-developed, pre- and poststorm monitoring plan, would offer insight for knowing when to intercede by initiating adaptive management protocols.

Workshop participants agreed that it would be helpful to establish some examples of the identified appropriate time lines for both oyster and coral reef construction and development of the living layer. To assess the feature success (rather than construction success), a different suite of metrics may need to be considered. These metrics may include, but are not limited to, how well the structural complexity mimics natural habitat or provides CSRM benefits, the successful survival of the reef species of interest (that is, coral or oyster), whether the feature is achieving its intended CRSM functions, and ecological performance.

Construction of reef NNBF may be more difficult because of potential short-term impacts to existing nearby corals or oyster that result from construction activities and potential long-term impacts to nearby reefs (and subsequent recruitment from them) if turbidity and sediment transport patterns change as a result of the construction. If a construction site is not scoped adequately, material placement during construction could bury or smother existing coral or oysters, causing an immediate negative impact. These negative impacts can be further exacerbated if the project includes an organism placement component. If the project relies on 
placement of organisms in addition to recruitment, then it is expected that a proportion of the transplanted organisms will not survive the transplant process. This fractional survivorship is anticipated even in the best of conditions. The introduction of increased turbidity or increased sediment accretion on the reef (during or after construction), however, can greatly reduce long-term organism survivorship. Generally, the workshop participants agreed that construction impacts for coral reefs were greater than those for oyster reef projects.

The group noted that ecological resources within the local project area can be affected by construction, but the actual presence of a species can also influence or prevent construction activities entirely. Threatened and endangered (T\&E) species or the presence of submerged aquatic vegetation (SAV) could limit site selection or construction timing. Knowledge of environmental windows, construction acoustic impacts, navigation activity, weather, and distribution of natural resources near the project site will help to inform development of a well-crafted construction plan that minimizes constraints to actual construction-related activities and potential impacts to resources.

\subsubsection{Operations, Monitoring, and Maintenance (OM\&M)}

All of the participants agreed that monitoring reef NNBF is valuable and necessary, especially after disturbance events such as storms, pollution discharge (for example, sewage or oiling), or overfishing. After storms, immediate mitigation may be required to adjust the built substrate or reef platform. Workshop participants identified a number of resources and guidance needed to help determine reef NNBF maintenance requirements. The most critical resources needed by the participants were case studies, historical data, and guidance on how to use data to inform new projects (Figure 3). Additional resource needs included understanding how to guide local sponsors and translation and interpretation of policy needs. In addition, the group questioned whether repair activities would be eligible for emergency funding under existing laws such as the Flood Control and Coastal Emergency Act ${ }^{1}$ (Public Law 84-99) or development of additional reef damage-insurance mechanisms. When asked whether nonfederal sponsors have the resources needed to conduct reef NNBF OM\&M, workshop participants indicated that such resources would be project specific

1. Flood Control Act of 1941, 33 U.S.C § 701n (2010). 
and depend on the sponsors' priorities as well as environmental inclinations. They also highlighted the importance of developing project partnerships with funding plans that included nongovernment organizations as well as local and state partners from the start of the project.

\subsubsection{Future directions}

After discussing the six topic areas, participants were asked to identify research priorities for wetlands and reefs. In brief, the group proposed that future directions in wetland and reef NNBF research and development should include the following: synthesis of existing literature and analysis of existing projects to better define failure modes, trigger points, and performance factors with respect to CSRM performance as well as ecological performance; focused research into the cobenefits of NNBF; and understanding to what end the response and resilience of NNBF affects economic costs throughout the life cycle of the project.

Research and knowledge of existing practices need to be synthesized and translated into guidance or case studies. A body of knowledge generated through academic communities as well as on-the-ground practitioners already exists, but that information has not been synthesized into a cohesive framework for USACE practitioners. Translating the existing knowledge base into a suite of documents (for example, short communications like technical notes) relevant to USACE would greatly benefit PDTs.

Workshop participants unanimously recognized that the suite of cobenefits conferred by NNBF were important to consider, but these benefits are difficult to identify, quantify, and monitor. There are existing works that discuss the identification of the cobenefits (Olander et al. 2015, 2018; Arkema et al. 2017), which should be reframed for USACE-specific projects. While other studies have quantified the flood protection and economic properties of NNBF (Arkema et al. 2015; Beck et al. 2018; Narayan et al. 2017; Reguero et al. 2018), more work is still needed to identify how these approaches can be used across USACE. Participants requested research that explicitly develops a methodology that quantifies the cost-effectiveness of NNBF as compared to structural measures. Studies that emphasize quantifying the failure modes and thresholds of both wetlands and reefs were discussed as priority research needs. Participants identified the need to better understand how NNBF fit within the spatial context of 
the surrounding ecosystem (that is, how to optimally design a spatial configuration of reefs) in relation to the shoreline and other reefs or how wetland performs if placed in different locations.

Participants also identified the need for improved technology transfer with regards to NNBF research and topics. The workshop revealed that a knowledge base regarding NNBF design and engineering does exist. However, that knowledge is not readily available to many engineers responsible for NNBF design and construction. Increased or improved technology transfer opportunities would allow for better communication and integration of both internal (that is, USACE) and external research efforts, which would expand insight into NNBF projects. Participants identified the utility of various technology transfer formats and designated technical manuals, technical notes, training courses, and workshops, webinars, and case studies as most useful (in descending order). More specifically, technology transfer priorities included the following:

- engineering analysis and design process manuals with examples for wetlands and reefs

- technical reports and notes on best practice design, incorporating NNBF into existing structural measures

- formal or ad hoc training courses for NNBF design

- webinars covering all aspects of the NNBF life cycle development of a repository for high quality NNBF case studies.

When considering the information discussed in the workshop, input offered from participants, and the establishment of technology transfer priorities, an important path forward is to develop best practice documents for the design and implementation of wetland and reef NNBF projects. 


\section{Conclusion}

USACE has a wealth of knowledge on the creation of wetlands and reefs, but the methodology and experience in constructing those projects needs to be synthesized into best practice documents for the design and implementation as NNBF. Understanding and forecasting the suite of cobenefits, including flood and coastal storm risk management, remains a major challenge and should be prioritized for research. Likewise, the true costs of $\mathrm{NNBF}$ throughout their life cycles need to be quantified in a manner that is comparable to life-cycle costs of structural measures. Overall, workshop participants were optimistic about incorporating NNBF into project planning but were more concerned with actual implementation across USACE. 


\section{References}

Arkema, Katie K., Steven B. Scyphers, Christine Shepard. 2017. "Living Shorelines for Nature and People.” In Shorelines: Living, Enhanced, Restored in the Modern Era. Eds. D.M. Bilkovic, M. Mitchell, J. Toft, M. La Peyre. Taylor \& Francis Group and CRC Press; CRC Press Marine Science Series.

Arkema, Katie K., Gregory M. Verutes, Spencer A. Wood, Chantalle Clarke-Samuels, Samir Rosado, Maritza Canto, Amy Rosenthal et al. 2015. "Embedding Ecosystem Services in Coastal Planning." Proceedings of the National Academy of Sciences 112(24): 7390-7395.

Beck, Michael W., Iñigo J. Losada, Pelayo Menéndez, Borja G. Reguero, Pedro DíazSimal, and Felipe Fernández. 2018. "The Global Flood Protection Savings Provided By Coral Reefs.” Nature Communications 9(1): 2186.

Daigneault, Adam, P. Brown, and D. Gawith. 2016 "Dredging versus Hedging: Comparing Hard Infrastructure to Ecosystem-Based Adaptation to Flooding." Ecological Economics 122:25-35.

Ferrario, Filippo, Michael W. Beck, Curt D. Storlazzi, Fiorenza Micheli, Christine C. Shepard, and Laura Airoldi. 2014. "The Effectiveness of Coral Reefs for Coastal Hazard Risk Reduction and Adaptation." Nature Communications 5(1): 1-9.

Ganju, Neil K., Zafer Defne, Matthew L. Kirwan, Sergio Fagherazzi, Andrea D’Alpaos, and Luca Carniello. 2017. "Spatially Integrative Metrics Reveal Hidden Vulnerability of Microtidal Salt Marshes." Nature Communications 8(1): 1-7.

Gedan, Keryn B., Matthew L. Kirwan, Eric Wolanski, Edward B. Barbier, and Brian R. Silliman. 2011. "The Present and Future Role of Coastal Wetland Vegetation in Protecting Shorelines: Answering Recent Challenges to the Paradigm.” Climatic Change 106(1): 7-29.

Hayes, D. F., T. J. Olin, J. C. Fischenich, and M. R. Palermo. 2000. Wetlands Engineering Handbook. ERDC/EL TR-WRP-RE-21. Vicksburg, MS: Engineer Research and Development Center.

Leonardi, Nicoletta, Iacopo Carnacina, Carmine Donatelli, Neil Kamal Ganju, Andrew James Plater, Mark Schuerch, and Stijn Temmerman. 2018. "Dynamic Interactions Between Coastal Storms and Salt Marshes: A Review.” Geomorphology 301:92-107.

Narayan, Siddharth, Michael W. Beck, Paul Wilson, Christopher J. Thomas, Alexandra Guerrero, Christine C. Shepard, Borja G. Reguero, Guillermo Franco, Jane Carter Ingram, and Dania Trespalacios. 2017. "The Value of Coastal Wetlands for Flood Damage Reduction in the Northeastern USA.” Scientific Reports 7(1): 9463. https://doi.org/10.1038/s41598-017-09269-z. 
Narayan, Siddharth, Michael W. Beck, Borja G. Reguero, Iñigo J. Losada, Bregje Van Wesenbeeck, Nigel Pontee, James N. Sanchirico, Jane Carter Ingram, GlennMarie Lange, and Kelly A. Burks-Copes. 2016. "The Effectiveness, Costs and Coastal Protection Benefits of Natural and Nature-Based Defences." PloS one 11(5): e0154735.

National Research Council. 2004. Analytical Methods and Approaches for Water Resources Project Planning. Washington, DC: The National Academies Press. https://doi.org/10.17226/10973.

Olander, Lydia, Heather Tallis, Steve Polasky, and Robert J. Johnston. 2015. Best Practices for Integrating Ecosystem Services into Federal Decision Making. Duke University, National Ecosystem Services Partnership.

Olander, Lydia P., Robert J. Johnston, Heather Tallis, James Kagan, Lynn A. Maguire, Stephen Polasky, Dean Urban, James Boyd, Lisa Wainger, and Margaret Palmer. 2018. "Benefit Relevant Indicators: Ecosystem Services Measures That Link Ecological and Social Outcomes." Ecological Indicators 85:1262-1272.

Perry, Chris T., Kyle M. Morgan, and Robert T. Yarlett. 2017. "Reef Habitat Type and Extent as Interacting Controls on Platform-Scale Carbonate Budgets." Frontiers in Marine Science 4(185). https://doi.org/10.3389/fmars.2017.00185.

Perry, Chris T., Paul S. Kench, M. J. O’Leary, K. M. Morgan, and F. Januchowski-Hartley. 2015. "Linking Reef Ecology to Island Building: Parrotfish Identified as Major Producers of Island-Building Sediment in the Maldives." Geology 43(6). https://doi.org/10.1130/G36623.1

Reguero, Borja G., Michael W. Beck, David N. Bresch, Juliano Calil, and Imen Meliane. 2018. "Comparing the Cost Effectiveness of Nature-Based And Coastal Adaptation: A Case Study from the Gulf Coast of the United States." PloS One 13(4): e0192132.

Rodwell, Lynda D., and Callum M. Roberts. 2000. Economic Implications of Fullyprotected Marine Reserves for Coral Reef Fisheries." In Collected Essays on the Economics of Coral Reefs. Kalmar, Sweden: Linnaeus University.

Sebens, K. P. 1991. "Habitat Structure and Community Dynamics in Marine Benthic Systems”. In Habitat Structure: The Physical Arrangement of Objects in Space. Eds., Susan S. Bell, Earl D. McCoy, and Henry R. Mushinsky. Amsterdam, Netherlands: Springer.

Stark, Jeroen, Yves Plancke, Stefaan Ides, Patrick Meire, and Stijn Temmerman. 2016. "Coastal Flood Protection by a Combined Nature-Based and Engineering Approach: Modeling the Effects of Marsh Geometry and Surrounding Dikes." Estuarine, Coastal and Shelf Science 175:34-45.

US Army Corps of Engineers. June 1987. Beneficial Use of Dredged Material. EM-1110-25026. Washington, DC: Department of the Army.

US Army Corps of Engineers. July 2015. Dredging and Dredged Material Management. EM-1110-2-5025. Washington, DC: Department of the Army. 
Vuik, Vincent, Saskia Van Vuren, Bas W. Borsje, Bregje K. van Wesenbeeck, and Sebastiaan N. Jonkman. 2018. "Assessing Safety of Nature-Based Flood Defenses: Dealing with Extremes and Uncertainties." Coastal Engineering 139:47-64. 


\section{Appendix}

\section{List of workshop attendees}

\begin{tabular}{|l|l|}
\hline Name & Affiliation \\
\hline Larry Oliver & North Atlantic Division-New England \\
\hline Lisa Winter & North Atlantic Division-New England \\
\hline Frank Buonaiuto & North Atlantic Division-New York \\
\hline Michael Morgan & North Atlantic Division-New York \\
\hline Susan Rice & North Atlantic Division-New York \\
\hline Monica Chasten & North Atlantic Division-Philadelphia \\
\hline Bob Griggs & North Atlantic Division-Philadelphia \\
\hline Vanessa Campbell & North Atlantic Division-Baltimore \\
\hline Angie Sowers & North Atlantic Division-Baltimore \\
\hline Michael Wolz & South Atlantic Division \\
\hline Angela Dunn & South Atlantic Division-Jacksonville \\
\hline Xaymara Serrano Vicente & South Atlantic Division-Jacksonville \\
\hline Jason Spinning & South Atlantic Division-Jacksonville \\
\hline Justin Goo & Pacific Ocean Division-Honolulu \\
\hline Siddharth Narayan & University of California-Santa Cruz \\
\hline Borja Reguero & University of California-Santa Cruz \\
\hline Safra Altman & Engineer Research and Development Center \\
\hline Carra Carrillo & Engineer Research and Development Center \\
\hline Mary Cialone & Engineer Research and Development Center \\
\hline Candice Piercy & Engineer Research and Development Center \\
\hline Emily Russ & Engineer Research and Development Center \\
\hline Todd Swannack & Engineer Research and Development Center \\
\hline John Winkelman & Engineer Research and Development Center \\
\hline
\end{tabular}




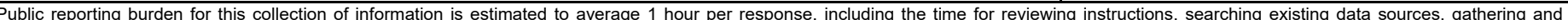

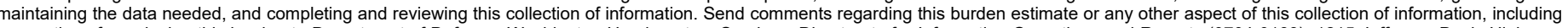

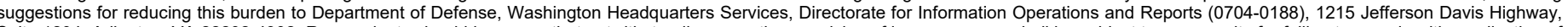

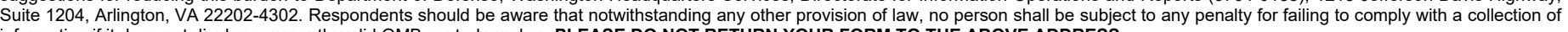
information if it does not display a currently valid OMB control number. PLEASE DO NOT RETURN YOUR FORM TO THE ABOVE ADDRESS.

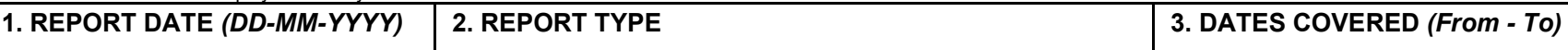

August 2021 Final

\section{TITLE AND SUBTITLE}

Expert Elicitation Workshop for Planning Wetland and Reef Natural and Nature-

Based Features (NNBF) Futures

5a. CONTRACT NUMBER

5b. GRANT NUMBER

5c. PROGRAM ELEMENT NUMBER

6. AUTHOR(S)

Candice D. Piercy, Safra Altman, Todd M. Swannack, Carra C. Carrillo,

Emily R. Russ, and John H. Winkelman

5d. PROJECT NUMBER

5e. TASK NUMBER

5f. WORK UNIT NUMBER

7. PERFORMING ORGANIZATION NAME(S) AND ADDRESS(ES)

US Army Engineer Research and Development Center

Environmental Laboratory

Coastal Hydraulics Laboratory

3909 Halls Ferry Road

3909 Halls Ferry Road

Vicksburg, MS 39180

Vicksburg, MS 39180

8. PERFORMING ORGANIZATION REPORT NUMBER

ERDC SR-21-4

9. SPONSORING / MONITORING AGENCY NAME(S) AND ADDRESS(ES)

US Army Corps of Engineers

Washington, DC 20314-1000

10. SPONSOR/MONITOR'S ACRONYM(S)

11. SPONSOR/MONITOR'S REPORT

NUMBER(S)

12. DISTRIBUTION / AVAILABILITY STATEMENT

Approved for public release; distribution is unlimited.

\section{SUPPLEMENTARY NOTES}

Funding Acct Code U4368940; AMSCO Code 031342

\section{ABSTRACT}

This special report discusses the outcomes of a September 2019 workshop intended to identify barriers to the consideration and implementation of natural and nature-based features (NNBF) in US Army Corps of Engineers (USACE) civil works projects. A total of 23 participants representing seven USACE districts, the US Army Engineer Research and Development Center (ERDC), and the University of CaliforniaSanta Cruz met at USACE's South Atlantic Division Headquarters in Atlanta, Georgia, to discuss how to facilitate the implementation of NNBF into USACE project planning for wetlands and reefs using six categories: (1) site characterization, (2) engineering and design analysis, (3) life-cycle analysis, (4) economic analysis, (5) construction analysis, (6) and operation and maintenance (and monitoring). The workshop identified seven future directions in wetland and reef NNBF research and development:

- $\quad$ Synthesize existing literature and analysis of existing projects to better define failure modes.

- Determine trigger points that lead to loss of feature function.

- Identify performance factors with respect to coastal storm risk management (CSRM) performance as well as ecological performance.

- Focus additional research into cobenefits of NNBF.

- Quantify the economic life-cycle costs of a project.

- Improve technology transfer with regards to NNBF research and topics.

\section{SUBJECT TERMS}

Environmental engineering_Congress Sustainable engineering-Congresses Wetlands Reefs

Storms Flood control

16. SECURITY CLASSIFICATION OF:

\section{a. REPORT}

Unclassified

\section{b. ABSTRACT}

Unclassified

\section{c. THIS PAGE}

Unclassified
17. LIMITATION OF ABSTRACT

18. NUMBER OF PAGES

SAR
37

\section{9a. NAME OF RESPONSIBLE PERSON}

19b. TELEPHONE NUMBER (include area code) 